\title{
VARIABLE CIRCULAR BEAM APERTURES
}

\author{
R. GLAS, J. HILCKER, H. MÜNZER, H. SCHNITTER and S. J. SKORKA \\ Beschleunigerlaboratorium der Universität und der \\ Technischen Universität München, 8046 Garching, Hochschulgelände, R.F.A.
}

\begin{abstract}
Résumé. - Nous décrivons deux types de diaphragmes variables utilisés dans le MP Tandem converti de Munich. L'un d'entre eux utilise 8 secteurs, dont 4 sont isolés afin de permettre des mesures de position du faisceau. A cause de son pouvoir de dissipation relativement faible, ce diaphragme est utilisé uniquement dans la région de basse énergie. L'autre type est un diaphragme à iris conçu pour une dissipation de grande puissance, afin de pouvoir l'utiliser dans le terminal. Le courant total de ce diaphragme peut être mesuré. Les deux diaphragmes peuvent être complètement fermés et peuvent donc être utilisés comme des cages de Faraday. Ils sont conçus avec les techniques de l'ultra-vide et peuvent être réchauffés jusqu'à $200^{\circ} \mathrm{C}$.
\end{abstract}

Abstract. - Two types of variable beam apertures used in the converted MP-Tandem at Munich are described. One of them uses eight sectors, four of which are insulated allowing beam position measurements. Due to its relatively small power dissipation this aperture is used only in the low energy region. The other type is an iris aperture designed for high power dissipation to be used in the terminal. The total beam current of this aperture can be measured. Both apertures can be completely closed and can therefore be used as Faraday cups. They are designed in UHV-techniques and can be baked at $200^{\circ} \mathrm{C}$.

Two types of variable and nearly circular apertures matched to the circular beam shape of the converted MP-Tandem were developed. The first type (Fig. 1) is called four sector aperture although it actually consists of eight sectors which are arranged in four planes allowing complete closure of the aperture.

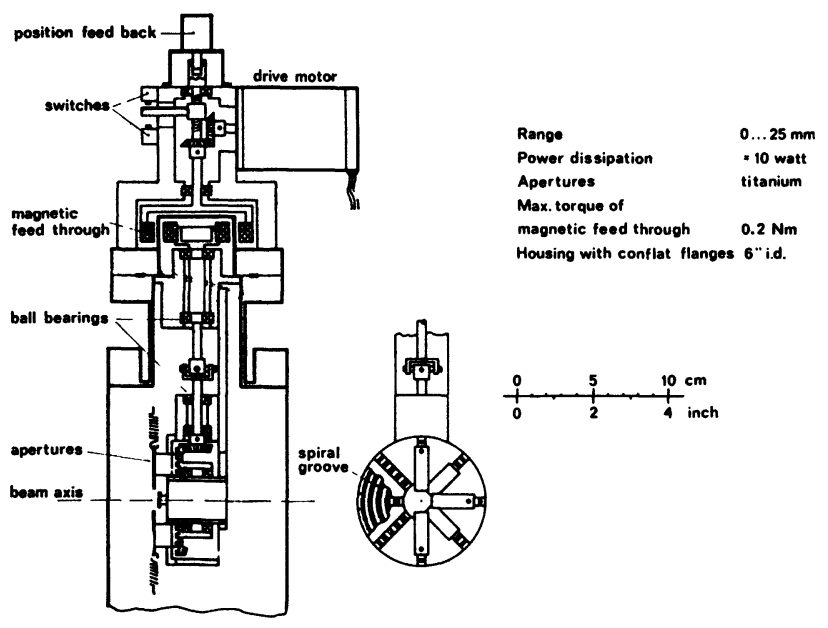

FIG. 1. - Variable four sector aperture with magnetic feedthrough and motor (schematic).

Four sectors are electrically insulated for individual beam current measurements. The four remaining sectors, completing the octagon, are grounded. The mechanical gear mechanism resembles the clamping device in a lathe.
The use in ultrahigh vacuum requires special care with regard to outgassing rates and friction. Materials used are stainless steel, titanium, aluminium and polyimide. Ball bearings are lubricated with $\mathrm{MoS}_{2}$. A prototype was cycled 80000 times at $5 \times 10^{-9}$ torr and temperatures up to $250^{\circ} \mathrm{C}$ without showing any wear. Without motor the assembly may be baked at $400{ }^{\circ} \mathrm{C}$. The maximum permissible power is estimated to be $10 \mathrm{~W}$. This restricts the use of this type of aperture to the low energy region of the accelerator.

Four of these apertures have been installed between injector and low energy tube entrance. Three of them - located after lens 1 [1], at the buncher waist and before lens 2 - are used to define precisely the emittance of the injected beam [2]. The apertures furthermore greatly facilitate and accelerate the handling of the beam, they are also used to vary beam intensities without touching the ion source controls. The current signals can be used to automatize the setting of corresponding steerers. No defects have occurred in half a year of routine operation.

The second type, designed to withstand high power loads, is an iris aperture (Fig. 2), similar to the shutter in a photographic camera. Eight segments move between fixed axles and a rotable cage. The segments are made from titanium, which retains its shape even at very high local temperatures. The cage rotates on ceramic balls to provide electrical insulation. Other materials used are stainless steel and polyimide.

The cage is moved by two radially magnetized permanent magnets, whose fields interact through the 

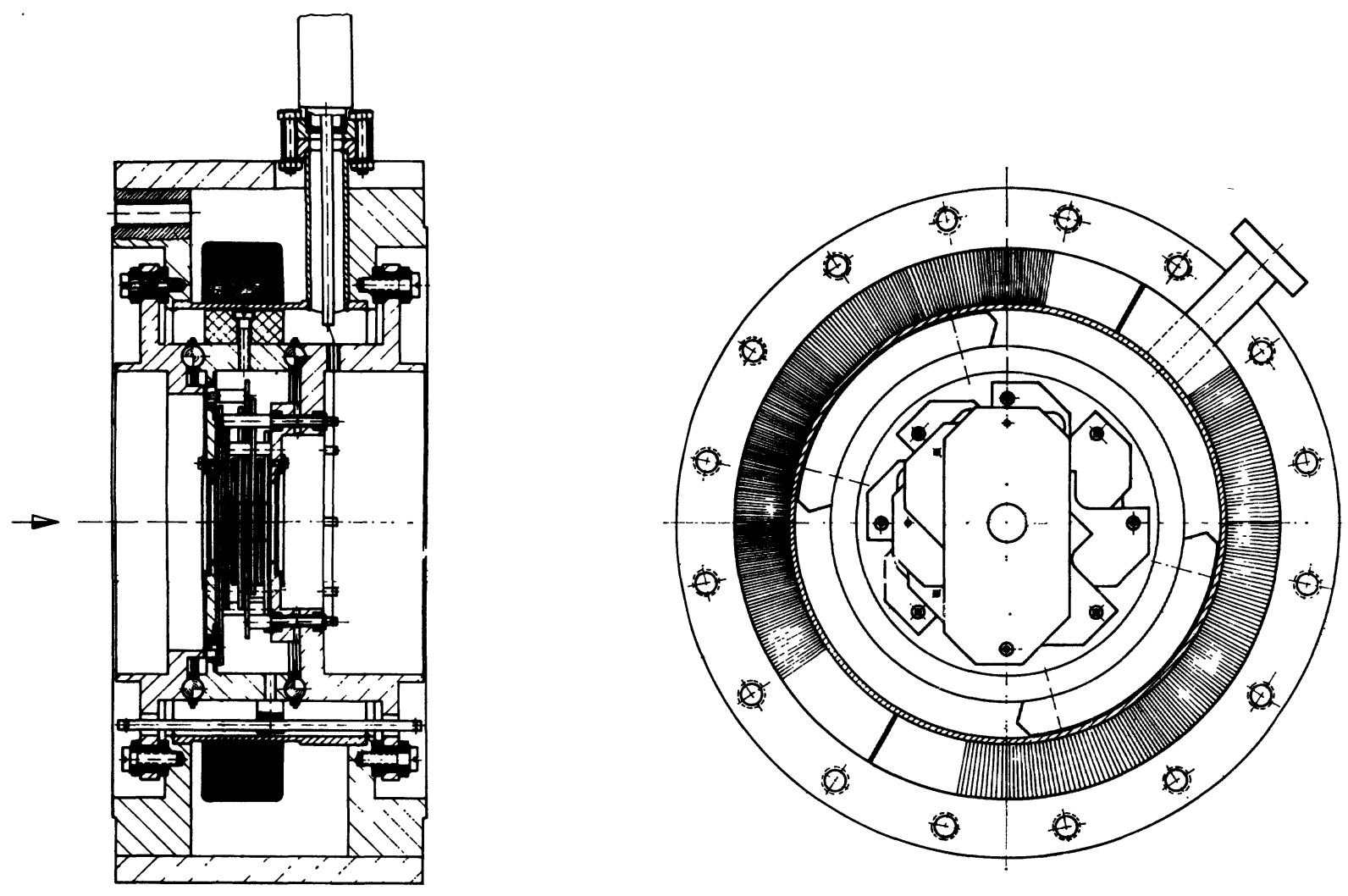

Iris Variable Aperture

$\begin{array}{ll}\begin{array}{l}\text { Aperture range } \\ \text { Power dissipation } \\ \text { (Radiation cooled) }\end{array} & \begin{array}{c}0-14 \mathrm{~mm} \\ \text { s } 200 \mathrm{~W}\end{array} \\ \begin{array}{l}\text { Required torque } \\ \text { Required power }\end{array} & \begin{array}{l}0.0 .6 \mathrm{Nm} \\ 0-20 \mathrm{~W} \\ \text { (+9Hz A.C. few W } \\ \text { to avoid hysteresis) }\end{array} \\ \begin{array}{l}\text { Apertures } \\ \text { All bearings }\end{array} & \begin{array}{l}\text { Titanium, } 1.5 \mathrm{~mm} \\ \text { Polyimid }\end{array}\end{array}$

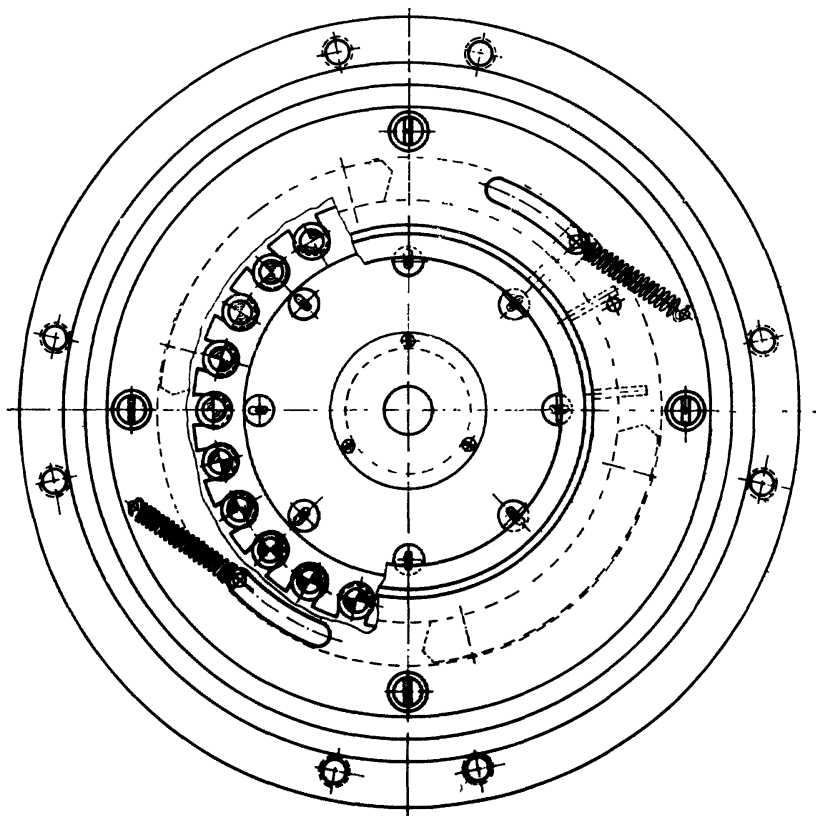

FIG. 2. - Iris aperture with drive system.

vacuum housing with the outer drive coil. The resulting angular momentum is proportional to the current through the coil and is counteracted by four springs. The diameter of the aperture therefore is also proportional to the current.

Figure 3 shows the control system for the iris aperture. To set the wanted diameter, a corresponding FM-signal is transmitted via light guide and is conver- ted to a proportional current. To guarentee undisturbed beam transmission in case of spark induced failures of the electronics, the last capacitively coupled stage operates on a.c. In case of any failures the coil therefore is always on zero current and the aperture is kept wide open by the springs. The aperture insert is insulated from the housing, the total beam current can be read out and transmitted to ground potential by 


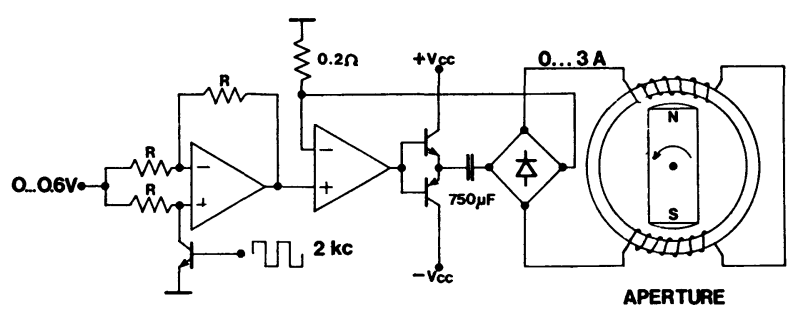

Fig. 3. - Control system for iris aperture.

means of a battery operated current-frequency converter and a light guide.
Two iris apertures were built and cycled 130000 resp. 180000 times in the $10^{-9}$ torr range at temperatures up to $215^{\circ} \mathrm{C}$ without showing any wear. Without coils the apertures were baked at $300{ }^{\circ} \mathrm{C}$. They have been installed in the terminal in front of the lens and the entrance of the high energy tube respectively. They define beam position and diameter. For very heavy ion beams both apertures help to suppress unwanted charge state components and prevent them from hitting the accelerator tube electrodes [1]. Used in the Faraday cup mode they are of great help in maximizing beam transmissions up to the terminal. No defects have occurred until now.

\section{References}

[1] Assmann W., et al., Nucl. Instrum. Methods 122 (1974) 191.

[2] SKorka S., Revue Phys. Appl. 12 (1977). 